\title{
Emergency surgical intervention for runaway atrial septal defect closure devices: A word of caution
}

Constantinos A. Contrafouris, MD, Andrew C. Chatzis, MD, Nicolas M. Giannopoulos, MD, Michael Milonakis, MD, Theofili Kousi, MD, George Kirvassilis, MD, and George E. Sarris, MD, Athens, Greece

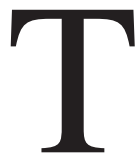

he use of occluder devices is gaining increasing popularity for the closure of secundum atrial septal defects (ASD) ${ }^{1-3}$ It is possible, however, that during its release from the introducing catheter, it will become misplaced or even embolize further and therefore require urgent surgical retrieval. We report 2 cases of attempted percutaneous transcatheter ASD closure complicated by embolization necessitating emergency surgical intervention.

\section{Clinical Summary}

PATIENT 1. An asymptomatic 24-year-old woman with an ASD underwent transesophageal echocardiography, which showed a 17to 19-mm-diameter ASD, and transvenous closure was attempted. A 43-mm Starflex device (NMT Medical, Inc., Boston, Mass) was implanted and seemed in good position. During extubation, the patient experienced an episode of ventricular tachycardia. Repeat transesophageal echocardiography showed translocation of the device and embolization into the right pulmonary artery. Transcatheter retrieval was unsuccessful (Figure 1). At emergency operation, the device was identified and retrieved through the right pulmonary artery through a transverse main pulmonary arteriotomy. The ASD was closed with direct sutures through a right atriotomy. The patient recovered without complications and remains well 6 years later.

PATIENT 2. An asymptomatic 11-year-old boy was found to have a large $(2.5 \times 2 \mathrm{~cm})$ ASD on transthoracic echocardiography. Transesophageal echocardiography was not performed. Transcatheter closure was attempted, and a 40-mm Amplatzer device (AGA Medical Corp., Golden Valley, Minn) was implanted. After the device was released, it slipped entirely into the left atrium, protruding into the mitral orifice. Retrieval efforts fraught with the risk of mitral disruption or occlusion were unsuccessful. At emergency operation, the ASD was found with no shelf at the inferior margin. The device, covered with recent red thrombus, had embolized entirely into the left atrium, lying on the anterior mitral valve leaflet protruding into its orifice and orientated toward the

From the Department of Pediatric and Congenital Heart Surgery, Onassis Cardiac Surgery Center, Athens, Greece.

Received for publication May 19, 2006; accepted for publication May 30, 2006.

Address for reprints: Constantinos A. Contrafouris, MD, Department of Pediatric and Congenital Heart Surgery, Onassis Cardiac Surgery Center, 356 Sygrou Ave, 17674 Kallithea, Athens, Greece (E-mail: ccontraf@ panafonet.gr).

J Thorac Cardiovasc Surg 2006; 132:1234-5

$0022-5223 / \$ 32.00$

Copyright $\odot 2006$ by The American Association for Thoracic Surgery doi:10.1016/j.jtcvs.2006.05.069

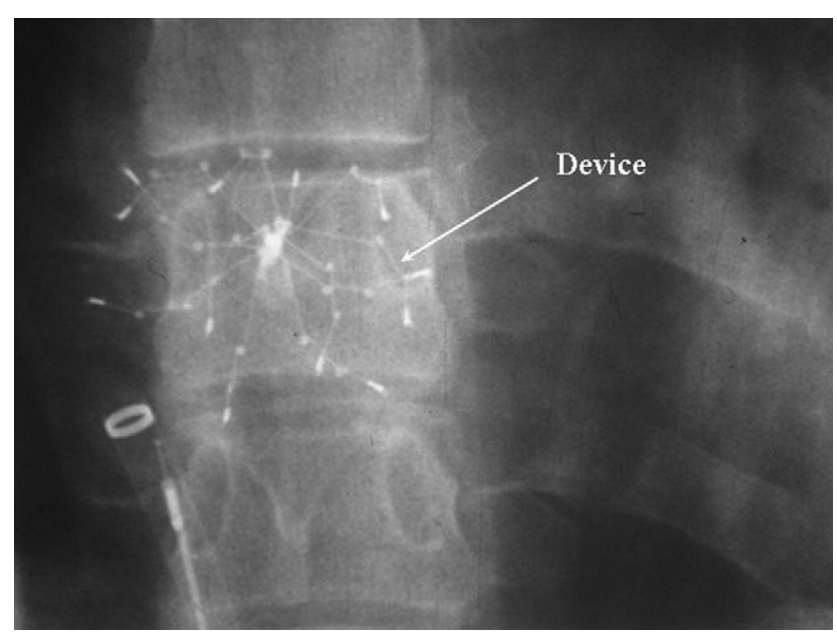

Figure 1. The Starflex device in the right pulmonary artery.

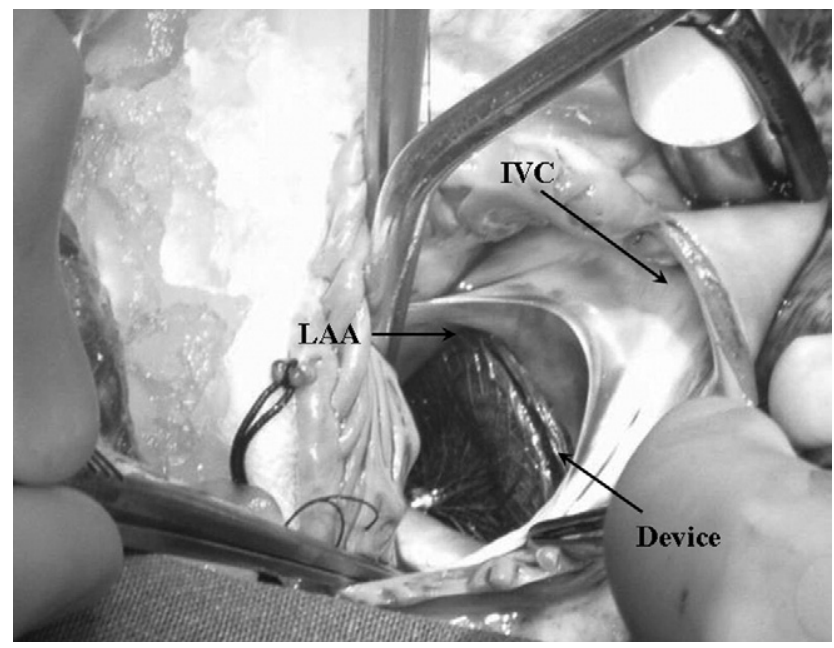

Figure 2. The Amplatzer device in the left atrium. LAA, Left atrial appendage; IVC, inferior vena cava.

left atrial appendage (Figure 2). Through the ASD, the device was retrieved without injury to the mitral valve, and the defect was closed with autologous pericardium. The patient had an uneventful recovery and was discharged a week later. He remains well at 1-year follow-up. 


\section{Discussion}

Transcatheter occlusion techniques have become an increasingly used alternative to surgical closure of the ASD, and various devices are available for this. ${ }^{1-3}$ Comparison of transcatheter and surgical closure of secundum ASD in children and adults reveals a lower complication rate in the device closure group. ${ }^{3,4}$ Moreover, in patients experiencing unsatisfactory device position, retrieval is usually feasible at the time of implantation, followed by elective surgical closure. If embolization (for which transcatheter retrieval is unsuccessful) occurs, urgent surgical therapy is necessary. ${ }^{2,3,5}$

The most important reason for acute failure of these devices is poor patient selection, device selection, or both. ${ }^{1,5}$ Other suggested mechanisms are device-related failure, inadequate experience, ${ }^{2,5}$ poor defect rim to hold the device, ${ }^{1-3}$ and tearing of the interatrial septum caused by catheter and device manipulation. ${ }^{2,5}$ A part or the entire device might embolize to the right or left atrium, main pulmonary artery, or even to other parts of the vascular tree on both the right and left sides of the circulation. Once the device is detached from its cable, it becomes difficult to retrieve, and depending on its location, it might even become lethal.

Although transcatheter devices represent useful alternatives to surgical closure in selected cases, they can be associated with failures and, most importantly, with life-threatening complications. Thus proper selection of patient and device is mandatory. Close monitoring and facilities for emergency surgical intervention should be available for all patients.

\section{References}

1. Berger F, Vogel M, Alexi-Meskishvili V, Lange P. Comparison of results and complications of surgical and Amplatzer device closure of atrial septal defects. J Thorac Cardiovasc Surg. 1999;118:674-80.

2. Chessa M, Carminatti M, Butera G, Binni RM, Drago M, Rosti L, et al. Early and late complications associated with transcatheter occlusion of atrial septal defect. J Am Coll Cardiol. 2002;39:1061-5.

3. Thomson J, Aburawi E, Watterson K, Van Doorn C, Gibbs J. Surgical and transcatheter (Amplatzer) closure of atrial septal defects: a prospective comparison of results and cost. Heart. 2002;87:466-9.

4. Du Zhong-Dong, Hijazzi Z, Kleinman C, Silverman N, Larntz K. Comparison between transcatheter and surgical closure of secundum atrial septal defect in children and adults. J Am Coll Cardiol. 2002;39: 1836-44.

5. Agarwal SK, Ghosh P, Mittal P. Failure of devices used for closure of atrial septal defects: mechanisms and management. $J$ Thorac Cardiovasc Surg. 1996;112:21-6.

\title{
Collision of the caval flows caused early failure of the Fontan circulation
}

\author{
Hirohisa Murakami, MD, ${ }^{a}$ Naoki Yoshimura, MD, ${ }^{a}$ Junichiro Kitahara, MD, ${ }^{a}$ Shingo Otaka, MD, ${ }^{a}$ Fikiko Ichida, MD, \\ and Takuro Misaki, MD, ${ }^{a}$ Toyama, Japan
}

I n 1988 , de Leval and colleagues ${ }^{1}$ demonstrated the importance of fluid dynamics in Fontan circulation. They developed the total cavopulmonary connection (TCPC), which has hemodynamic advantages compared with the traditional atriopulmonary connection. In regard to the hemodynamics of the cavopulmonary anastomosis, several studies demonstrated that collision of caval flows at the connection resulted in high dissipative energy losses and that introduction of an offset between the superior vena cava (SVC) and the inferior vena cava (IVC) inlets reduced those losses. ${ }^{2,3} \mathrm{We}$ describe an early failure of the Fontan circulation caused by collision of the caval flows.

From the First Department of Surgery and Pediatrics, ${ }^{\mathrm{b}}$ Faculty of Medicine, University of Toyama, Toyama, Japan.

Received for publication June 23, 2006; accepted for publication Aug 11, 2006.

Address for reprints: Hirohisa Murakami, MD, First Department of Surgery, Faculty of Medicine, University of Toyama, Toyama 2630, Sugitani, Toyama, 930-0194, Japan (E-mail: murahisa@med.u-toyama.ac.jp).

J Thorac Cardiovasc Surg 2006;132:1235-6

$0022-5223 / \$ 32.00$

Copyright $\odot 2006$ by The American Association for Thoracic Surgery doi:10.1016/j.jtcvs.2006.08.006

\section{Clinical Summary}

The patient was a 2-year-old girl with a diagnosis of tricuspid atresia made soon after birth, for which a bidirectional Glenn (BDG) anastomosis was performed at the age of 7 months. Preoperative catheterization data showed a mean pulmonary artery (PA) pressure of $13 \mathrm{~mm} \mathrm{Hg}$, pulmonary vascular resistance of 3.8 $\mathrm{U} / \mathrm{m}^{2}$, Nakata's PA index of 252 , and left ventricular ejection fraction of 58\%. Angiography showed that mitral valve regurgitation was not present. The site of the BDG anastomosis was deviated to the left side over the vertebra (Figure 1), suggesting that a Fontan-type operation could be safely performed. Two months after the catheterization, extracardiac TCPC was completed with interposition of an expanded polytetrafluoroethylene graft $(\varphi 18 \mathrm{~mm})$ between the right PA and the IVC. After Fontan circulation was established, the patient demonstrated low cardiac output syndrome; her heart rate was 190 beats/min and systolic blood pressure ranged from 50 to $60 \mathrm{~mm} \mathrm{Hg}$. Despite the use of inhaled nitric oxide therapy, the transpulmonary pressure gradient between the central venous pressure (17-19 $\mathrm{mm} \mathrm{Hg}$ ) and the left atrial pressure $(2-3 \mathrm{~mm} \mathrm{Hg})$ increased. Immediate echocardiography showed marked dilatation of the IVC and collapse of the left ventricular cavity. No blood flow was detected in the extracardiac conduit. Urgent angiography was performed. Impingement of SVC flow onto IVC flow and marked stagnation of blood flow in the 